\title{
Mikrospawanie laserowe
}

\author{
Laser microwelding
}

\section{Streszczenie}

W artykule przedstawiono podstawy mikrospawania laserowego. Jest to bardzo precyzyjna technika łączenia materiałów znajdująca bardzo szerokie zastosowanie w przemyśle. Wytwarzanie mikro i mezo elementów należy dzisiaj do jednego z wiodących nurtów wytwarzania, dlatego też mikrospawanie laserowe znajduje coraz większe zastosowanie i stanowi obszar intensywnych badań. W procesie tym powstaje spoina która swymi wymiarami nie przekracza $1 \mathrm{~mm}$. Ze względu na specyfikę oddziaływania laserowego strefa wpływu ciepła jest niewielka w stosunku do innych technik spawania. Do mikrospawania laserowego używa się laserów impulsowych $\mathrm{Nd}: \mathrm{YAG}, \mathrm{CO}_{2}$ lub laserów światłowodowych. Mikrospawanie jest procesem powtarzalnym, dającym efektywne spoiny i poddającym się automatyzacji.

Słowa kluczowe: laser; spawanie; spajanie; mikrospawanie

\begin{abstract}
The paper presents some aspects of laser micro-welding. It is a very precise technique of joining materials which finds very wide application in the industry. The production of micro and meso elements is today one of the leading trends of manufacturing, so laser micro-welding is widely used in industry and is an area of intensive research. Dimensions of the welds formed in this process do not exceed 1 $\mathrm{mm}$. Due to the specificity of the laser beam the heat affected zone is small in relation to other welding techniques. For laser micro-welding pulsed laser $\mathrm{Nd}$ YYAG, $\mathrm{CO}_{2}$ or fiber laser are used. Laser micro-welding is a repetitive process which gives an effective weld and which gives to automate.
\end{abstract}

Keywords: laser; welding; bonding; micro-welding

\section{Wstęp}

Wytwarzanie mikroukładów jest obecnie jedną z najważniejszych części każdego nowoczesnego przemysłu. Ze względu na bardzo szerokie zastosowanie wykorzystuje się w nim całą gamę różnego typu technologii. Wśród nich poczesne miejsce zajmuje spawanie będące jedną z głównych technik łączenia elementów. Odmianą bardzo często wykorzystywaną w mikroelektronice i produkcji układów mikromechanicznych jest mikrospawanie laserowe. Oferuje ono wysoką jakość spoiny, brak konieczności stosowania dodatkowych topników, a także ograniczoną strefę wpływu ciepła. Istotną zaletą tej metody jest możliwość łączenia różnego typu materiałów, a także nowo tworzonych materiałów kompozytowych czy polikrystalicznych. Powstała spoina ma niewielką objętość, wysoką trwałość, a sam proces jest stabilny i powtarzalny [1]

Mikrospawanie laserowe jest cały czas rozwijającą się dziedziną i nadal stanowi obszar intensywnych badań. Ma bardzo szeroki obszar zastosowań od przemysłu motoryzacyjnego, lotniczego i kosmicznego poprzez przemysł elektroniczny, aż do medycznego $[1 \div 3,5]$. Mikrospawanie może być także wykorzystywane do regeneracji różnego typu form, matryc i stempli, zwłaszcza tych stosowanych do wytwarzania mikroukładów.

\section{Mikrospawanie laserowe}

Mikrospawanie laserowe to precyzyjna, wszechstronna i zaawansowana technika wytwarzania, która jest obecnie stosowana w wielu obszarach przemysłu. W tej odmianie techniki spawania laserowego zarówno rozmiar spoiny jak i jej głębokość nie przekracza $1 \mathrm{~mm}$. Do tego typu operacji można stosować lasery $\mathrm{Nd}: Y A G, \mathrm{CO}_{2}$ lub lasery światłowodowe $[1,2,8,9]$. W trakcie mikrospawania energia promieniowania laserowego jest deponowana w bardzo krótkim czasie na bardzo małej powierzchni, dlatego moce używanych laserów nie mogą być zbyt duże $(100-200 \mathrm{~W})$. Dodatkowo mała średnica plamki rzędu od kilku do kilkudziesięciu mikrometrów pozwala na bardzo precyzyjną pracę $[4,5]$. W czasie procesu wymagany jest bardzo dobry kontakt pomiędzy spawanymi elementami $[1,9]$. Proces mikrospawnia laserowego jest krótszy niż konkurencyjne metody łączenia mikroelementów i nie występuje w nim zużycie narzędzia. W przypadku automatyzacji procesu mikrospawania czas operacji łączenia elementów jest z reguły krótszy niż czas ich ustawienia w strefie obróbki. Do najważniejszych zalet mikrospawania laserowego można zaliczyć [1,2]:

- precyzyjne połączenie o wysokiej jakości spoinie

- mała strefa wpływu ciepła, co prowadzi do minimalizacji zmian w strukturze fizykochemicznej łączonych elementów - duża prędkość procesu

Dr inż. Piotr Lipiec - Instytut Technologii Maszyn i Automatyzacji Produkcji, Wydział Mechaniczny, Politechnika Krakowska. Autor korespondencyjny/Corresponding author: lipiec@mech.pk.edu.pl 
- duża elastyczność systemu pozwalająca na przenoszenie systemu laserowego między stanowiskami

- spawanie może być wykonywane w różnych geometriach i między materiałami o różnych grubościach.

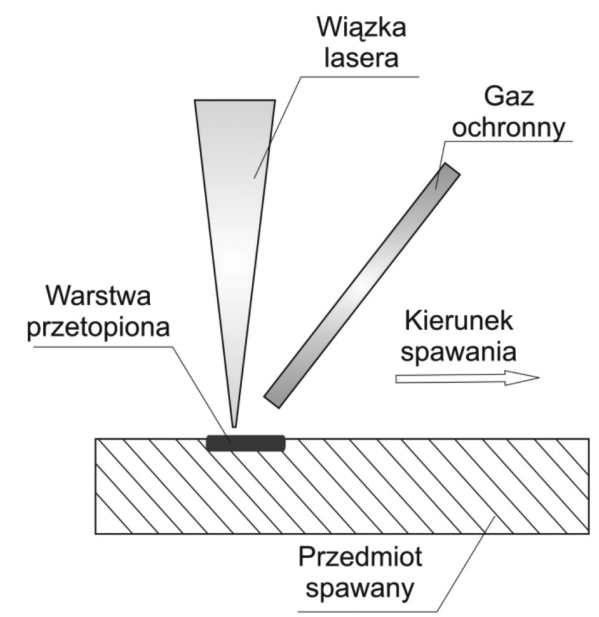

Rys. 1. Schemat mikrospawania laserowego

Fig. 1. Scheme of laser microwelding

W trakcie procesu światło laserowe jest absorbowane przez powierzchnię materiału, który ulega następie roztopieniu, co prowadzi do powstania spoiny. Na rysunku 1 przedstawiony jest schemat mikrospawania laserowego. Najlepsze efekty uzyskuje się przy zastosowaniu laserów impulsowych, które charakteryzują się dużą energią przekazywaną w jednym impulsie. $Z$ reguły proces mikrospawania zachodzi w atmosferze gazów osłonowych, co zabezpiecza przed reakcją przetapianego materiału ze składnikami powietrza. Powstałe połączenia charakteryzują się niewielką objętością i wysoką trwałością [1 $\div 3]$.

\section{Lasery stosowane w mikrospawaniu}

W mikrospawaniu można stosować różnego typu lasery. Do najczęściej spotykanych należą impulsowe lasery $\mathrm{Nd}: Y$ -

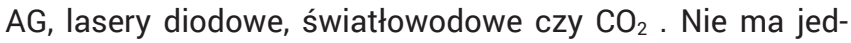
nego uniwersalnego lasera, który podoła wszystkim zadaniom związanym z mikrospawaniem. Wybór odpowiedniego zależy od rodzaju spawanych materiałów, precyzji spawania, możliwości doprowadzenia promienia laserowego do obszaru roboczego czy kosztu całego systemu laserowego. Za każdym razem stosowany system laserowy musi być dobrany do konkretnego przypadku uwzględniającego jego specyfikę. Istotną cechą jest typ promieniowania użytego lasera uwzględniającą stopień absorpcji danej długości fali przez spawany materiał, energię przekazywaną w impulsie czy średnicę plamki [7]. Odpowiedni dobór tych parametrów pozwala na uzyskanie dużej gęstości energii na spawanej powierzchni, zmniejszonej strefy wpływu ciepła oraz dużej prędkości procesu. Poniżej zostanie przedstawiona krótka charakterystyka trzech wybranych typów laserów.

\section{Laser $\mathrm{CO}_{2}$}

Laser $\mathrm{CO}_{2}$ jest laserem gazowym, w którym ośrodek czynny stanowi dwutlenek węgla. Pod wpływem wyładowań elektrycznych dochodzi do wzbudzeń oscylacyjno-rotacyjnych cząsteczek ośrodka, które wracając do stanu stabilnego, emitują fotony. Długość uzyskiwanej fali to 10,6 $\mu \mathrm{m}$. Mogą one pracować w trybie ciągłym lub impulsowym. Moce uzyskiwane przez lasery gazowe wynoszą od kilkudziesięciu wat do kilkuset kilowatów.

\section{Laser Nd:YAG}

Jest to laser oparty na ciele stałym. W tym przypadku jest to kryształ aluminiowo itrowy domieszkowany neodymem. Akcja laserowa zachodzi w wyniku pompowania optycznego, co powoduje emisję fotonów przez kryształ. Długość uzyskiwanej fali to $1064 \mathrm{~nm}$. Lasery te mogą pracować w trybie ciągłym i impulsowym. Stosując odpowiednie układy optyczne można zmniejszać długość uzyskiwanej fali, co daję możliwość polepszenia absorpcji dla różnych materiałów. Ze względu na ośrodek czynny, laser Nd: YAG ma bardziej kompaktowe wymiary niż lasery gazowe, co w wielu zastosowaniach ma bardzo duże znaczenie. Moce uzyskiwane w impulsie są rzędu setek watów. Przy pracy impulsowej można uzyskać częstotliwość pracy rzędu kiloherców, co pozwala uzyskać dużą gęstość energii w jednym impulsie przy stosunkowo małej mocy.

\section{Laser światłowodowy}

Laser światłowodowy jest to laser, w którym ośrodek czynny stanowi światłowód będący z reguły domieszkowany pierwiastkami ziem rzadkich. Akcja laserowa zachodzi w wyniku pompowania optycznego diodami laserowymi. W przypadku np. lasera erbowego długość uzyskanej fali to m.in. - 1,4 $\mu \mathrm{m}$. Laser światłowodowy ma niewielkie wymiary i można go bezpośrednio podłączyć do światłowodu, co pozwala na bardzo swobodne operowanie wiązką laserową. Jest rozwiązaniem tańszym i wygodniejszym w użyciu niż dwa poprzednie typy laserów. Można uzyskać bardzo szeroki zakres mocy od kilkudziesięciu wat do dziesiątek kilowatów, jednak wzrost mocy wiąże się ze wzrostem rozmiarów i kosztów urządzenia. Laser ten można chłodzić powietrzem, co również zmniejsza koszty jego eksploatacji, dodatkowo charakteryzuje się on dużą niezawodnością i stabilnością wiązki.

\section{Spawanie materiałów różnego typu}

W wielu zastosowaniach przemysłowych zachodzi konieczność wykonywania połączeń między różnymi metalami. Stanowi to bardzo poważny problem, który spowodowany jest wieloma czynnikami. Do najważniejszych należy zaliczyć różne właściwości fizyczne łączonych metali takie jak temperatura topnienia, gęstość czy przewodność cieplna. Dlatego, aby uzyskać dobre połączenie należy odpowiednio dobrać metale, tak, aby krytyczne z punktu widzenia spawania właściwości były do siebie zbliżone. W przypadku złego doboru materiału może dochodzić do powstawania kruchych połączeń międzymetalicznych. Istotne jest,

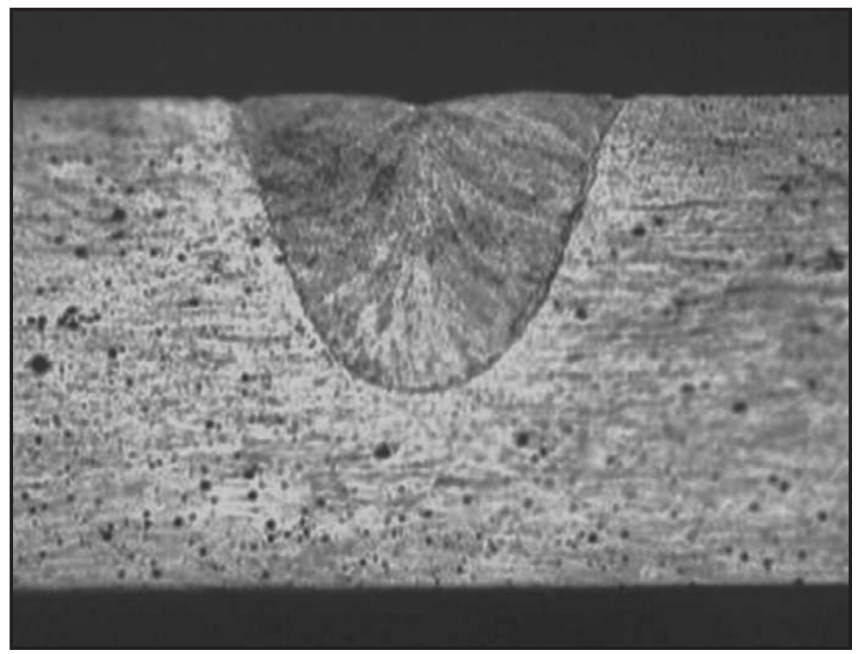

Rys. 2. Spoina powstała w wyniku mikrospawania laserem Nd:YAG [1] Fig. 2. Example of weld joint made with Nd:YAG pulsed laser [1] 
aby objętość przetopionego materiału była jak najmniejsza. Powstały po przetopieniu spaw z reguły jest heterogeniczny chemicznie, chociaż mogą powstawać struktury homogeniczne, jednak jest to rzadkością. Jest to spowodowane różnymi właściwościami spawanych materiałów, których dobór wynika z konieczności wykonania połączenia, a nie uzyskania konkretnego stopu [1].

Do mikrospawania materiałów różnego typu stosuje się najczęściej impulsowe lasery Nd:YAG $[1,2,9]$. Ze względu na swoją charakterystykę bardzo dobrze nadają się do tego typu operacji. Jako że w każdym impulsie jest przekazywana bardzo duża energia, można dokładnie kontrolować temperaturę w obszarze spawania, co pozwala na kontrolę głębokości, a także szerokości powstałego spawu. Również charakterystyka impulsu, czyli bardzo szybkie narastanie na jego początku i szybkie opadanie na jego końcu powoduje, że proces przetapiania następuje $\mathrm{w}$ bardzo krótkim czasie, dzięki czemu można uzyskać dobrą spoinę (rys. 2).

Oprócz laserów Nd:YAG można wykorzystywać do mikrospawania różnych materiałów lasery światłowodowe. Pozwalają one na uzyskanie większej gęstości mocy, mniejszej strefy wpływu ciepła, a także mniejszej objętości przetopionego materiału.

W rzeczywistości mikrospawanie materiałów różnego typu jest trudne do wykonania w warunkach przemysłowych i nadal znajduje się na etapie intensywnych badań, a ilość komercyjnych zastosowań tej odmiany jest znikoma [1].

\section{Defekty połączeń}

W procesie mikrospawania laserowego bardzo często łączone elementy mają niewielkie wymiary, co powoduje, że proces wymaga zastosowania bardzo dużej precyzji zarówno z punktu widzenia doboru parametrów, jak i zastosowanego oprzyrządowania. Błędy w planowaniu i wykonaniu mogą prowadzić do powstania defektów w otrzymanej spoinie $[1,2]$.

W trakcie mikrospawania laserowego mogą powstawać defekty połączeń charakterystyczne dla procesu spawania takie jak pęknięcia, rozpryski, przepalenia, porowatość itp. (rys. 3.) Są one spowodowane najczęściej utlenianiem, zbyt wysoką temperaturą przetopienia lub źle dobraną temperaturą do spawanych stopów, a także źle dobraną długością impulsu lasera (lub czasem nagrzewania w przypadku laserów o działaniu ciągłym). W przypadku spawania różnego typu materiałów dochodzą defekty wywołane ich różnymi właściwościami fizycznymi (rys. 4).

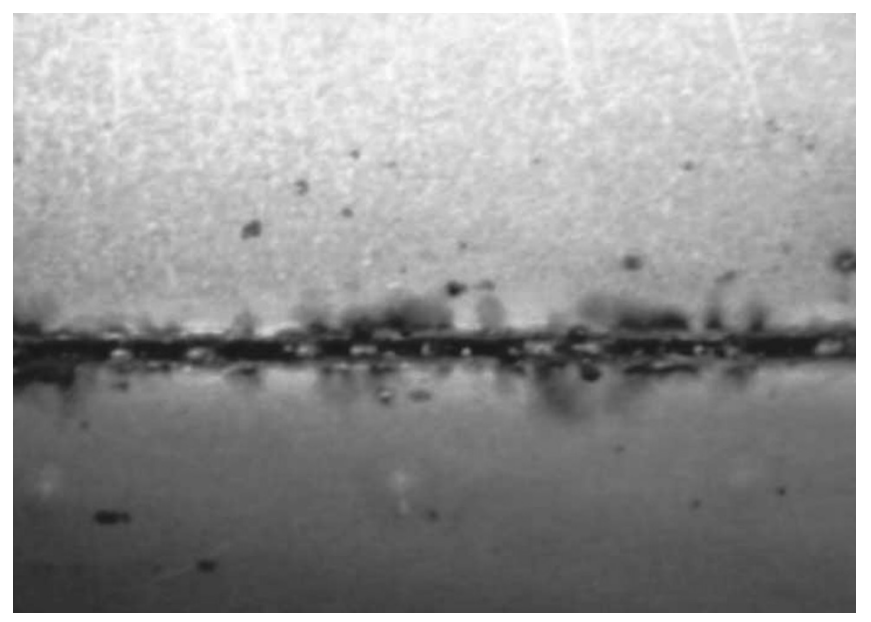

Rys. 3. Porowatość i rozpryski powstałe w wyniku nieodpowiedniego doboru parametrów [1]

Fig. 3. Porosity and spatter formed during laser welding [1]

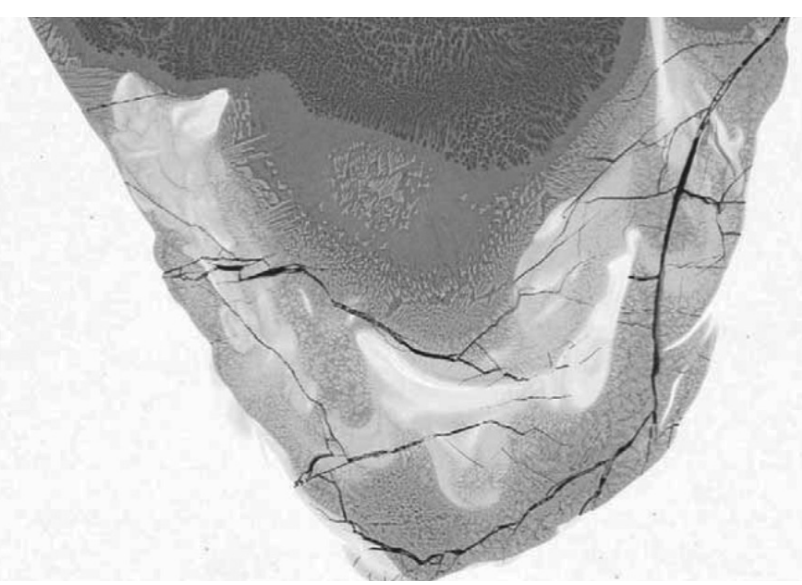

Rys. 4. Obraz SEM mikropęknięć. Spoina między stopem aluminium a miedzią [1]

Fig. 4. SEM micrograph of the micro cracking. The weld between aluminium alloy and pure copper [1]

Sposobem na pozbycie się defektów jest odpowiedni dobór parametrów spawania, a także zastosowanie odpowiedniego oprzyrządowania. Dodatkowo, aby uniknąć defektów, wprowadza się osłonę z gazów obojętnych, co pozwala na wyeliminowanie procesu utleniania, czy wpływu zanieczyszczeń pochodzących z powietrza, co w przypadku mikrospawania ma duże znaczenie $[1,2,9]$.

\section{Zastosowanie mikrospawania laserowego}

Mikrospawanie laserowe pozwala na bardzo dokładną kontrolę procesu, zapewnia jego stabilność, powtarzalność, a także daje się łatwo automatyzować. Niewielka strefa wpływu ciepła, kontrolowana temperatura, a także
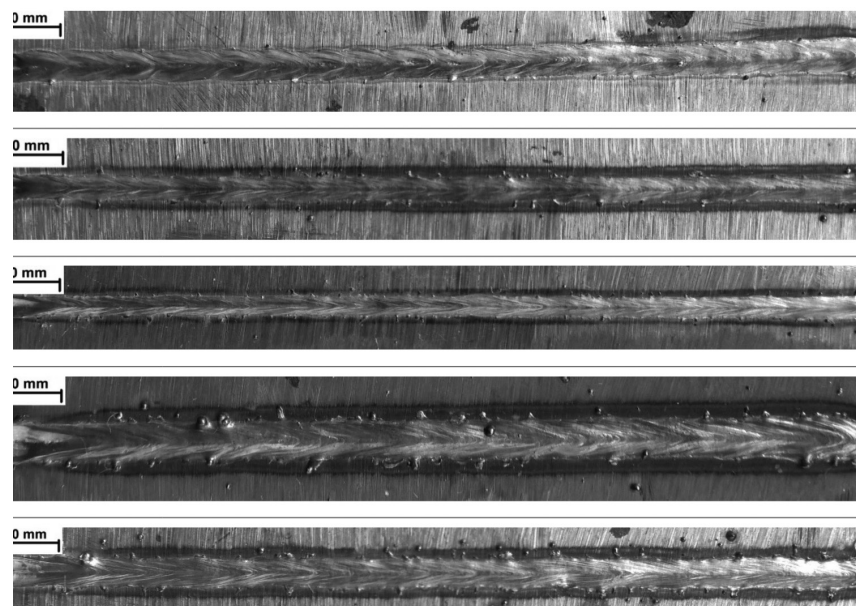

Rys. 5. Kapsułki z radioizotopami spawane laserowo [1]

Fig. 5. Laser welded capsules with radioactive isotopes [1]

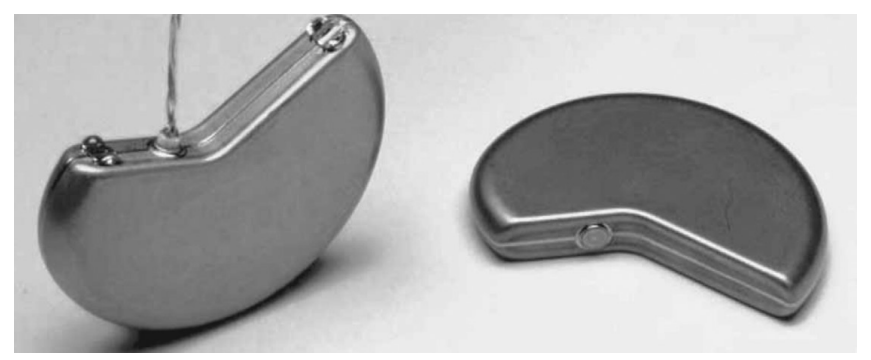

Rys. 6. Kapsułki z radioizotopami spawane laserowo [1]

Fig. 6. Laser welded capsules with radioactive isotopes [1] 
niewielkie objętości powstałej spoiny oraz jej zwartość pozwala na stosowanie tej techniki w bardzo wielu obszarach wytwarzania (rys. 5 i 6). Najczęściej jest ona stosowana w przemyśle [1,2]:

- samochodowym (układy MEMS w poduszkach powietrznych, układach zapłonowych, bateriach itp.),

- medycznym (aparaty słuchowe, rozruszniki serca, narzędzia chirurgiczne, implanty itp.),

- elektronicznym (dyski twarde, telefony komórkowe, ogniwa paliwowe i słoneczne itp),
- w jubilerstwie, wytwarzaniu czujników, w produkcji MEMS.

Mikrospawanie laserowe jest wykorzystywane wszędzie tam, gdzie wymagana jest duża precyzja wykonanego połączenia, jego hermetyczność (w przypadku zamkniętych elementów jak obudowy np. ogniw paliwowych czy rozruszników serca), oraz niewielki rozmiar wykonanej spoiny. W przypadku łączenia mikroelementów elektronicznych i elektromechanicznych jest właściwie jedyną dostępną technologią, którą można w łatwy sposób automatyzować.

\section{Podsumowanie}

Mikrospawanie laserowe jest obecnie dynamicznie rozwijającą się i bardzo szeroko stosowaną techniką łączenia elementów. Ze względu na postępującą miniaturyzację jest stosowane w praktycznie każdej gałęzi przemysłu. Jej właściwości sprawiają, że powstająca spoina ma małą objętość, dużą wytrzymałość, a strefa wpływu ciepła jest niewielka. Proces ten bardzo dobrze nadaje się do automatyzacji. Najczęściej wykorzystuje się w nim impulsowe lasery Nd:YAG i światłowodowe, które ze względu na swoją kompaktową budowę pozwalają na konstrukcję zwartych i elastycznych stanowisk roboczych.

Do najważniejszych wyzwań stojących przed tą techniką jest dobre opanowanie spawania różnego typu materiałów o różnych właściwościach fizycznych i mechanicznych nie tylko w skali laboratoryjnej, ale i w realiach produkcyjnych. Lepsze zrozumienie procesu pozwoli na wykonywanie wysokiej jakości spawów dla szerokiej gamy różnego typu materiałów.

\section{Literatura}

[1] M. Naeem, "Developments in laser microwelding technology" Woodhead Publishing Limited, 2013.

[2] S. Matsuoka, Y. Okamoto, A. Okada, "Influence of weld bead geometry on thermal deformation in laser micro-welding" Procedia CIRP 6, s.492-497, 2013.

[3] X. Jang, S. Chandrasekar, C. Wang, "A laser microwelding method for assembly of polymer based microfluidic devices" Optics and Lasers in Engineering 66, s.98-104, 2015.

[4] A. Hozoorbakhsh, M. I. S. Ismail, N. B. A. Aziz, "A computational analysis of heat transfer and fluid flow in high-speed scanning of laser microwelding" International Communications in Heat and Mass Transfer 68, s. 178-87, 2015.

[5] A. Hozoorbakhsh, M. I. S. Ismail, A. A. D. M. Sarhan, A. Bahadoran, N. B. A. Aziz "An investigation of heat transfer and fluid flow on laser micro-welding upon the thin stainless steel sheet (SUS304) using computational fluid dynamics (CFD)" International Communications in Heat and Mass Transfer 75 s.328-340, 2016.

[6] D. Triantafyllidis, M.J.J. Schmidt, L. Li, "Comparison of high power diode laser and Nd:YAG laser microwelding of k-type thermocouples" Journal of Materials Processing Technology 138 s.102-108, 2003.

[7] S. Kaierle, L. Overmeyer, C. Hoff, P. Herzog, J. Hermsdorf, “Conditioning of copper material surfaces increasing the efficiency of continuous wave laser microwelding" CIRP Journal of Manufacturing Science and Technology 14 s.66-70, 2016.

[8] I. Geoffray, R. Bourdenet, M. Theobald, "Laser Micro-welding" Applied to Target Manufacturing. Physics Procedia 12 s.363-369, 2011.

[9] S. Nakashiba, Y. Okamoto, T. Sakagawa, S. Takai, A. Okada, "Micro-welding of Copper Plate by Frequency Doubled Diode Pumped Pulsed Nd:YAG Laser.. Physics Procedia 39 s.577-584, 2012. 